Revista Tecné, Episteme y Didaxis: TED. Año 2014, Número Extraordinario. ISSN Impreso: 0121-3814, ISSN web: 2323-0126 Memorias, Sexto Congreso Internacional sobre Formación de Profesores de Ciencias. 08 al 10 de octubre de 2014, Bogotá

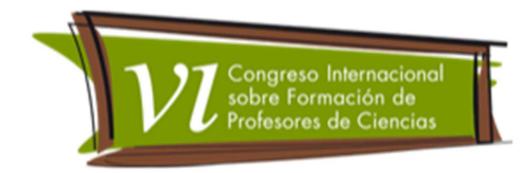

\title{
Jogo das Tribos: uma experiência na EFA Puris - Araponga, MG
}

Stelzer, Juliana Deprá1; Salgado, Lucas Braga de Ávila² ; Bontempo, Gínia Cezar³

Categoria 1. Reflexiones y experiencias desde la innovación en el aula.

\section{Resumo}

O trabalho relata o desenvolvimento do "Jogo das Tribos" durante o Estágio Supervisionado da Licenciatura em Ciências Biológicas na Escola Família Agrícola (EFA) - Puris em Araponga, MG. O objetivo da dinâmica foi simular a realidade e a relação ser humano-ser humano de forma lúdica, envolvendo questões como comunicação, linguagens, relações sociais e de poder, tomadas de decisão, preconceitos e coletividade. A experiência reuniu 51 estudantes das $1^{\underline{a}}, 2^{\underline{a}}$ e $3^{\underline{a}}$ séries do Ensino Médio da EFA e três monitores. Teve duração de duas horas, divididas em dois momentos: jogo e discussão. Foi uma vivência transdisciplinar que permitiu um olhar crítico e diverso sobre a realidade. A experiência e 0 estágio em sua totalidade contribuíram para consolidar a nossa identidade docente e nos fez enxergar a importância do compromisso dos educadores com a transformação social.

\section{Palavras chaves}

Transdisciplinaridade; Jogo; Formação de Professores.

\section{Introdução}

A experiência aqui relatada partiu do interesse dos estudantes/autores em desenvolver um jogo durante o Estágio Supervisionado da Licenciatura em Ciências Biológicas na Escola Família Agrícola (EFA) Puris em Araponga, MG.

O jogo em questão, chamado de "Jogo das Tribos" é um Live Role Play Game (Live RPG, jogo de interpretação de personagens que envolvem movimentação e cenário), idealizado por colegas estudantes de Ciências Biológicas da Universidade Estadual Paulista (UNESP), Campus Rio Claro, SP. Os estudantes/autores tiveram a oportunidade de conhecer e participar do jogo que fez parte da programação do IV Curso de Formação Política da Biologia (CFPBio), promovido pela Entidade Nacional de Estudantes de Biologia (ENEBio)nos dias 04 a 08 de setembro de 2013, em Piracicaba, SP. 
Revista Tecné, Episteme y Didaxis: TED. Año 2014, Número Extraordinario. ISSN Impreso: 0121-3814, ISSN web: 2323-0126 Memorias, Sexto Congreso Internacional sobre Formación de Profesores de Ciencias. 08 al 10 de octubre de 2014, Bogotá

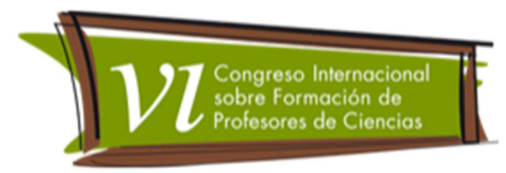

O jogo foi proposto como parte das atividades do Estágio Supervisionado com o intuito de levantar, entre outras questões, discussões sobre preconceitos, entre eles o racial, e seus meios de disseminação em nossa sociedade. A atividade aconteceu no dia 18 de novembro de 2013, durante o Serão, espaço diário na EFA reservado para atividades diferenciadas, como exibição de filmes, debates e apresentações culturais.

Compreendemos que mesmo tratando-se de aulas de Biologia, a discussão sobre a realidade cultural, social e política pode ser trabalhada com os estudantes e de maneira transdisciplinar. Assumimos transdisciplinaridade como "àquilo que está ao mesmo tempo entre as disciplinas, através das diferentes disciplinas e além de qualquer disciplina. Seu objetivo é a compreensão do mundo presente para o qual um dos imperativos é a unidade do conhecimento" (Nicolescu, 1999).

Acreditamos que o papel do educador na construção de conhecimentos e valores não deve se limitar ao conteúdo formal e disciplinar, mas criar espaços que possibilitem reflexões sobre a realidade e coloquem os educandos como sujeitos que fazem parte da mesma, e que por isso podem atuar para transformála. Nesse contexto, o Estágio Supervisionado como espaço reservado para prática e reflexões, possibilita a construção e o desenvolvimento da nossa identidade docente.

Nos identificamos com Boal (2011) quando ele diz que a arte não serve apenas para mostrar como é o mundo, mas também para mostrar porque ele é assim e como se pode transformá-lo. No Jogo das Tribos os participantes se transportam para outro mundo e vivem a história dos personagens. Ao viver um personagem com visão de mundo e modos de ser específicos, os participantes podem refletir sobre suas próprias visões de mundo e modos de ser e se questionar, e aos outros, sobre conceitos já estabelecidos.

Além disso, jogos e teatro contribuem para desenvolvimento de processos de aprendizagem e trocas de conhecimento de maneira lúdica e criativa, que explorem outras formas de expressão, relações e comportamento.

Neste trabalho pretendemos compartilhar a experiência do Jogo das Tribos desenvolvido na EFA-Puris, cujos objetivos foram simular a realidade e a relação ser humano-ser humano de forma lúdica, envolvendo questões como comunicação, linguagens, relações sociais e de poder, tomadas de decisão, preconceitos e coletividade. 
Revista Tecné, Episteme y Didaxis: TED. Año 2014, Número Extraordinario. ISSN Impreso: 0121-3814, ISSN web: 2323-0126 Memorias, Sexto Congreso Internacional sobre Formación de Profesores de Ciencias. 08 al 10 de octubre de 2014, Bogotá

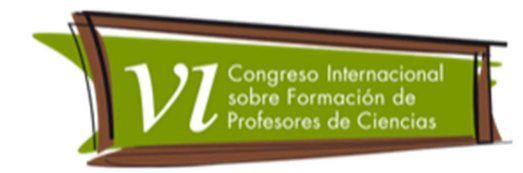

\section{Desenvolvimento}

A experiência será relatada em três partes. Num primeiro momento esclarecemos informações gerais sobre o jogo, em seguida relatamos a organização do jogo na EFA e nossas observações sobre como se deu e ao final discorremos sobre a discussão. Infelizmente, as regras do jogo na íntegra não serão discorridas por apresentarem uma riqueza de detalhes. Os interessados podem procurar os autores para receberem, via email, o arquivo com o roteiro completo do Jogo das Tribos.

Informações sobre o Jogo das Tribos

A história que os participantes vivem é um contexto de guerra que ocorreu no último verão entre três tribos: Viúvas Negras, Búfalos e Lobos. Ao final desta estação, todos estão com sérios problemas internos e precisam uns dos outros para sobreviver.

Os personagens são: membros das tribos, oráculos e espíritos. Cada tribo possui um oráculo, incumbido de fornecer elementos a respeito da história, características de seus grupos e informações distorcidas dos outros. Os espíritos são responsáveis por esclarecer as regras do jogo previamente e coordená-lo até o fim, intervindo sempre que necessário.

Os grupos podem possuir características, organização própria e ferramentas específicas. Todos eles iniciam o jogo com uma problemática a ser resolvida, e deverão vencer os preconceitos atribuídos a outras tribos no início do jogo se quiserem atingir seus objetivos.

Uma informação importante foi ocultada às tribos: elas precisam uma das outras para resolver seus desafios, mas não devem saber disso. É necessário que os participantes tenham medo e preconceito da outra tribo para que realmente haja uma barreira a ser superada.

Para o jogo acontecer é necessária uma preparação prévia dos espíritos e oráculos. Somente esses personagens conhecem os reais objetivos do jogo e precisam atuar para que estes sejam alcançados.

Os materiais necessários são cartolinas, canetas (ou carvão), panos de cores diferentes para sinalizar as tribos e outros materiais específicos que caracterizem cada grupo (especificados no roteiro). 
Revista Tecné, Episteme y Didaxis: TED. Año 2014, Número Extraordinario. ISSN Impreso: 0121-3814, ISSN web: 2323-0126

Memorias, Sexto Congreso Internacional sobre Formación de Profesores de Ciencias. 08 al 10 de octubre de 2014, Bogotá

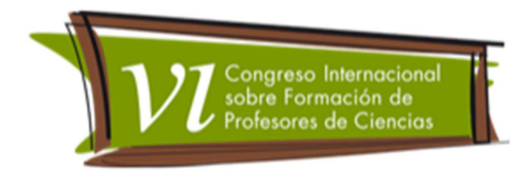

O cenário é composto por três territórios e uma área de livre transitação (Figural). A interação entre membros em diferentes territórios é restrita: não pode ocorrer toque ou trocas de itens. Na área de livre transitação, só é permitida a comunicação entre as tribos por meio de gestos e desenhos nas cartolinas. A fala só é permitida com os espíritos, seus oráculos e entre membros da mesma tribo, mas somente dento de seus territórios. Após o início do jogo, as tribos têm 10 minutos para demarcar seus territórios com objetos dispostos no local (ex: galhos, cordas).

Figura 1. Cenário do Jogo das Tribos

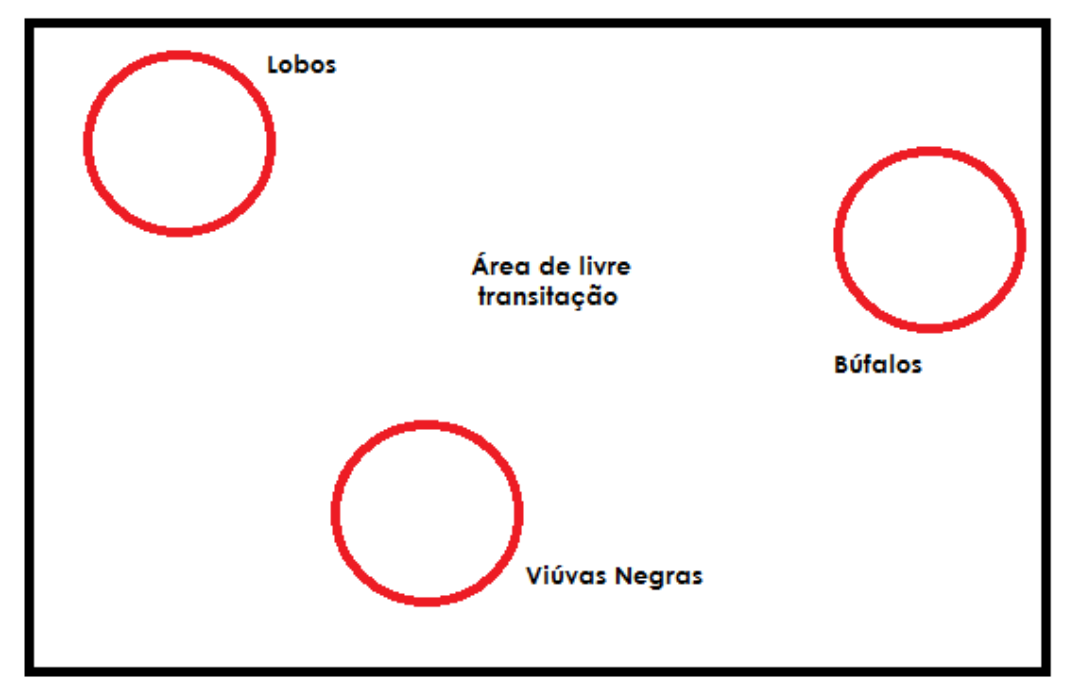

O jogo dura uma hora e meia e é dividido em três estações: primavera, outono e inverno. Cada estação dura 30 minutos e os oráculos só aparecem em suas tribos em duas estações. A chegada do próximo verão marca o fim do jogo, e os espíritos consultam as tribos para verificar como lidaram com seus desafios. Ao final é realizada uma discussão com perguntas geradoras sobre o jogo.

\section{O jogo na EFA}

O Jogo das Tribos agrupou 51 estudantes das 1aㅗ $2^{a}$ e $3^{a}$ séries do Ensino Médio da EFA e três monitores das disciplinas Biologia, Geografia e Extensão Rural. 
Revista Tecné, Episteme y Didaxis: TED. Año 2014, Número Extraordinario. ISSN Impreso: 0121-3814, ISSN web: 2323-0126 Memorias, Sexto Congreso Internacional sobre Formación de Profesores de Ciencias. 08 al 10 de octubre de 2014, Bogotá

Reunimo-nos anteriormente com os monitores e esclarecemos os objetivos e regras da atividade. Cada um recebeu o roteiro adaptado pelos autores com explicações gerais da dinâmica e informações específicas de sua tribo.

Em seguida, os participantes se reuniram no pátio da escola e as informações gerais sobre a dinâmica foram apresentadas. Os educandos foram divididos nas três tribos, os oráculos representados pelos monitores e os espíritos, pelos autores. A atividade teve duração de duas horas, dividida em dois momentos: jogo e discussão.

No início do jogo os participantes focaram na criação de identidade com o grupo. As falsas informações disseminadas pelos oráculos dificultaram a interação e a relação de confiança entre eles.

Logo na primeira estação, alguns indivíduos das Viúvas Negras, temendo os Lobos que possuíam 'armas' (de mentira), buscaram materiais que encontraram no pátio e iniciaram uma briga. Os espíritos interferiram e enfatizaram que o contato corporal e a violência não eram permitidos. Essa atitude evidenciou a dificuldade em lidar com a comunicação sem a fala e como temiam ser enganados pelas outras tribos. O clima de desconfiança entre eles era grande. Casos como esse são passiveis de acontecer, pois os jogadores se encontram imersos em uma história e passam a agir como sujeitos da mesma. Por isso, é necessário que os espíritos estejam vigilantes e presentes, para evitar que excessos ocorram.

As cartolinas foram bem utilizadas pelas tribos, com desenhos e representações. Expressões corporais também foram exploradas por meio de gestos, mímicas e uso de onomatopéias.

Na segunda estação os grupos já tinham percebido a relação de dependência entre si, mas não sabiam como resolver a problemática, pois não confiavam uns nos outros e consideravam-se rivais.

A tribo dos Búfalos permaneceu unida e na defensiva em seu território a maior parte do tempo. Seus membros só saíam de seu território em grupo. As tribos das Viúvas Negras e dos Lobos se mostraram desorganizadas e dispersas, com ações espontâneas e individuais para estabelecer comunicação e acordos com as outras tribos. Apenas um pequeno grupo discutia as estratégias, coletivamente.

Ao final da terceira estação, antes do próximo verão, as tribos conseguiram resolver seus desafios. Todos participaram ativamente e se empenharam em 
Revista Tecné, Episteme y Didaxis: TED. Año 2014, Número Extraordinario. ISSN Impreso: 0121-3814, ISSN web: 2323-0126 Memorias, Sexto Congreso Internacional sobre Formación de Profesores de Ciencias. 08 al 10 de octubre de 2014, Bogotá

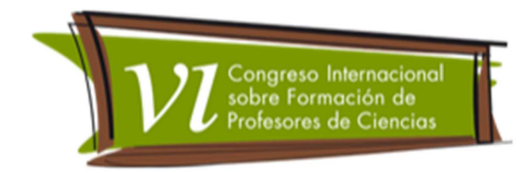

resolver suas problemáticas, mesmo sem compreender os reais objetivos da dinâmica, que ficaram claros após a discussão.

\section{Discussão}

Fizemos uma grande roda de discussão e pedimos para falarem sobre o jogo e a resolução do problema. Membros da tribo das Viúvas Negras e dos Lobos relataram a falta de organização e confusões geradas ao elaborar estratégias das tribos. Segundo eles, isto dificultou a realização de ações coletivas e concretas, bem como a compreensão das regras do jogo. Cada um tentava resolver o problema por si só e a troca de informações dentro de cada tribo ficou prejudicada. Membros dos Búfalos disseram que estavam bem unidos e resolviam tudo coletivamente. Esse fato foi avaliado positivamente por membros do próprio grupo, mas colegas das outras tribos ressaltaram que esses ficaram muito tempo em seu território e interagiram pouco com os demais.

Levantamos a questão da comunicação, questionando os educandos sobre como se sentiram ao ter a fala limitada. Eles sentiram dificuldades e vários momentos de tensão foram criados por mal entendidos. Um ponto positivo foi o estímulo a outras formas de interações não verbais, em que a criatividade precisou ser explorada.

O episódio da violência praticada pelos Lobos e Viúvas Negras no início do jogo também foi discutido, e os questionamos sobre a necessidade dessa atitude. Alguns justificaram apontando as características apresentadas pelos oráculos, que alimentavam o medo e a rivalidade entre as tribos. Eles disseram que era uma solução "mais fácil" para conseguir o que queriam da outra tribo, pois negava o diálogo na resolução do problema.

Pedimos para um membro de cada tribo falar o que sabia dos outros grupos e em seguida descreveriam suas reais características. A partir daí, os participantes perceberam que os oráculos contavam falsas histórias a respeito dos outros grupos. Ficaram surpresos com as mentiras, se sentiram enganados e perceberam que não precisavam temer uns aos outros.

Após os esclarecimentos perguntamos se isso acontecia em nossa sociedade e quem e/ou o quê seriam os oráculos. As respostas apontaram a mídia, principalmente por meio da televisão, a polícia e o Estado como oráculos de nossa sociedade. Os estudantes e monitores presentes discutiram que esses instrumentos e instituições se constroem num mundo permeado de relações 
Revista Tecné, Episteme y Didaxis: TED. Año 2014, Número Extraordinario. ISSN Impreso: 0121-3814, ISSN web: 2323-0126 Memorias, Sexto Congreso Internacional sobre Formación de Profesores de Ciencias. 08 al 10 de octubre de 2014, Bogotá

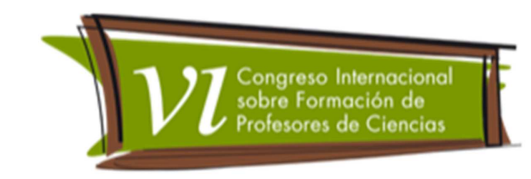

sociais e de poder desiguais e atuam disseminando preconceitos que influenciam na formação de consciência da população. Alguns preconceitos discutidos foram o racial, contra os negros; a discriminação sofrida pelas mulheres; e até preconceitos contra os jovens do campo e às escolas rurais.

A partir da experiência concluiu-se que o Jogo das Tribos é uma ferramenta rica que permite uma reflexão sobre nossas ações na sociedade, sobre a (des)valorização do diálogo e a forma como lidamos com a construção de preconceitos. A metáfora do oráculo cumpriu a função de evidenciar as relações de poder e as desigualdades que permeiam nossas vidas. Foi, portanto, uma vivência transdisciplinar que permitiu um olhar crítico e diverso sobre a realidade.

A realização do jogo exprime o que refletimos sobre o estágio realizado na EFA em sua totalidade, quando concluímos que essa experiência contribuiu para consolidar a nossa identidade enquanto educadores e nos fez enxergar a importância do compromisso dos educadores com a transformação da sociedade (Salgado, Stelzer, Bontempo, \& Pacheco, 2014).

Sim, é possivel trabalhar de forma transdisciplinar e inovadora. Porém exige tempo para pensar, planejar e executar, bem como autonomia para desenvolver momentos de aprendizagem diferenciados.

Esperamos que a partir do relato, outros educadores conheçam a experiência e sintam-se motivados a vivê-la em suas diferentes realidades e contextos.

\section{Referências Bibliográficas}

Boal, A. (2011). Jogos para atores e não-atores. Rio de Janeiro: Civilização Brasileira.

Nicolescu, B. (1999). O Manifesto da Transdisciplinaridade. São Paulo: Triom.

Salgado, L.B.A., Stelzer, J.D., Bontempo, G.C., \& Pacheco, J.C.A. (2014, abril). A importância da vivência de educação no campo na formação de professores. Anais do II Congresso Nacional de Formação de Professores e XII Congresso Estadual Paulista sobre Formação de Educadores, São Paulo, SP, Brasil. 